\title{
ANÁLISE DAS INFLUÊNCIAS EXISTENTES ENTRE QUALIDADE DE VIDA E QUALIDADE DE VIDA NO TRABALHO: ESTUDO COM COLABORADORES DA INDÚSTRIA DE LATICÍNIOS
}

\section{ANALYSIS OF INFLUENCES EXISTING BETWEEN QUALITY OF LIFE AND QUALITY OF WORK LIFE: A STUDY WITH COLLABORATORS IN THE DAIRY INDUSTRY}

\author{
Rúbia Carla Maier ${ }^{1}$; Guataçara dos Santos Junior ${ }^{2}$; Luciana da Silva Timossi ${ }^{3}$ \\ ${ }^{1}$ Universidade Tecnológica Federal do Paraná - UTFPR - Ponta Grossa - Brasil \\ rubiacmaier@yahoo.com.br \\ ${ }^{2}$ Universidade Tecnológica Federal do Paraná - UTFPR - Ponta Grossa - Brasil \\ guatajr@uol.com.br \\ ${ }^{3}$ Universidade Tecnológica Federal do Paraná - UTFPR - Ponta Grossa - Brasil \\ lucianatimossi@yahoo.com.br
}

\begin{abstract}
Resumo
$O$ objetivo do presente artigo é analisar a influência existente entre os critérios da qualidade de vida no trabalho $(Q V T)$ com a qualidade de vida $(Q V)$ geral, e entre os domínios da $Q V$ com a $Q V T$ em colaboradores da indústria de laticínio. Identificando quais os critérios e os domínios significantes e dependentes. Metodologia: os dados de qualidade de vida e qualidade de vida no trabalho de 548 colaboradores são provenientes da pesquisa realizada por Timossi (2009) através da aplicação simultânea dos instrumentos WHOQOL-100 e adaptação do modelo de Walton para o português. As análises ocorreram com o teste de independência em 14 variáveis. Os resultados apontaram que existe influência entre os 8 critérios da QVT com a QV geral, e entre 5 domínios de QV com a QVT geral. Somente o domínio "Aspectos Espirituais e crenças", não apresentou influência significativa com a QVT. Concluí-se que todos os critérios da QVT possuem influência na $Q V$ dos colaboradores avaliados, como também com os domínios da $Q V$, com exceção do domínio "Aspectos Espirituais e crenças", influenciam significativamente na QVT. A empresa poderá direcionar investimentos nos domínios da $Q V$ em busca de reflexos na QVT, pois foi verificada a influência existente entre ambas, este investimento estará gerando satisfação tanto para a empresa quanto para seus colaboradores.
\end{abstract}

Palavras-chave: qualidade de vida; qualidade de vida no trabalho; teste de independência; laticínios.

\section{Introdução}

A competição existente no mercado empresarial está fazendo com que as organizações mudem seus moldes organizacionais, na busca acirrada por produtividade e resultados melhores. 
Nesta mudança, do cenário organizacional, pode-se ressaltar a maior participação das pessoas na prospecção dos negócios.

Considerando que as pessoas passam parcela significativa de suas vidas em organizações, pesquisadores e gestores crescentemente passaram a se preocupar com a qualidade de vida no trabalho (QVT), buscando aumentar a satisfação e a motivação do trabalhador e com isso refletir no aumento da produtividade.

A QVT segue em busca de atingir vários níveis, proporcionando a saúde física, social e psicológica a seus colaboradores, podendo contar com programas e ações, realizando de forma consciente com a realidade de sua organização. Destinando de maneira correta os investimentos para que realmente gerem bons resultados.

A gestão deve estabelecer aos colaboradores mudança de hábitos, incentivando-os a buscarem a qualidade de vida (QV) dentro e fora das organizações. Para Shinyashiki (2002), as pessoas não conseguem equilibrar trabalho e vida pessoal, pensam somente em sucesso e não lembram de serem felizes.

Para que a empresa possa proporcionar o equilíbrio entre o trabalho e vida pessoal, segundo Shinyashiki (2002) é importante que todas as partes estejam comprometidas, sem compromisso essas idéias não passam de sonhos escritos na missão das empresas.

Para Timossi (2009) a ideia de correlacionar a QVT e QV está de acordo com a premissa atual de gestão de pessoas, pois possibilita avaliar a influência de qualquer critério de QVT sobre a QV geral e também inversamente.

Este estudo tem como objetivo analisar a influência existente entre os critérios da QVT na QV geral e dos domínios da QV na QVT geral nos colaboradores da indústria de laticínio do estado do Paraná, utilizando o teste de independência. Identificando quais os critérios e os domínios significantes e dependentes.

\section{Investigação quanto a QV e a QVT}

A QV assume importância cada vez maior e está sendo foco de vários estudos, inclusive voltados ao ambiente de trabalho. Timossi (2009) ressalta que mesmo a QV sendo um tema atual e muito discutido, não existe um conceito único que seja capaz de abordar os vários fatores que interferem ou a influenciam.

A partir de vários desenvolvimentos realizados pela Organização Mundial da Saúde (OMS) em torno do assunto qualidade de vida, chegou-se a definição de que é a percepção do indivíduo de sua posição na vida, da sua cultura e sistema de seus valores nos quais ele vive e em relação aos seus objetivos, expectativas, padrões e preocupações (WHOQOL GROUP, 1998). 
Percebe-se que a QV engloba todas as esferas contidas na vida em geral de um indivíduo, Minayo; Hartz; Buss,(2000) completam que QV é uma noção eminentemente humana, que tem sido aproximada ao grau de satisfação encontrado na vida familiar, amorosa, social e ambiental e à própria estética existencial.

Neste contexto de QV, o trabalho é que vem ocupar um grande espaço na vida das pessoas, focadas nesta ideia muitas organizações vêm desenvolvendo estratégias com objetivo de estabelecer um equilíbrio entre a relação vida e o trabalho.

As concepções sobre o ser humano no ambiente de trabalho vêm sendo transformado no decorrer dos anos, o termo QVT vem sendo empregado e debatido por muitas empresas na busca de um diferencial. A QVT tem sido uma preocupação do homem desde o início de sua existência, às vezes apresentada com outros títulos, mas sempre voltada para trazer satisfação e bem-estar ao trabalhador ao executar suas tarefas (RODRIGUES, 2008).

Com o avanço e desenvolvimento industrial e as transformações ocorridas no trabalho, o homem deixou de ser visto como uma máquina, numa concepção que se voltava apenas para a produtividade, passando-se a um olhar em que a satisfação dos colaboradores reverte-se em melhor desempenho e eficiência para o sucesso das empresas.

Entretanto, verifica-se que estas transformações no trabalho motivadas pela acirrada concorrência entre as organizações, exige profissionais qualificados, aumentando a produtividade com metas excessivas, o que vem prejudicado a saúde e a vida das pessoas. Shinyashiki (2002) fala que viver somente para o trabalho, em um regime de competição eterna, está custando um preço altíssimo, sendo chocante a quantidade de doenças contrai devido a um estilo de vida que impossibilita o indivíduo de ser feliz.

O foco na QVT se torna importante devido o trabalho ocupar um grande espaço na vida das pessoas. De acordo com Conte (2003), a importância da QVT reside no fato de que as pessoas passam em ambiente de trabalho mais de 8 horas por dia, durante pelo menos 35 anos de suas vidas.

Torna-se difícil para o indivíduo separar os problemas profissionais de sua vida pessoal, como também inversamente. O trabalho conforme Martel e Dupuis (2006) ocupa os pensamentos, determina o cronograma para o dia, fornece o acesso para o consumidor aos produtos e contribui para a identidade social.

Para Martel e Dupuis (2006), a QVT corresponde a uma condição experimentada pelo indivíduo na busca dinâmica de seus objetivos hierarquicamente organizados, dentro dos domínios de trabalho, onde a redução do espaço que separa o indivíduo a partir destes objetivos é refletida por um impacto positivo na qualidade de vida geral, no desempenho organizacional e, consequentemente, no funcionamento global da sociedade. 
A ideia da QVT é proporcionar um ambiente de trabalho saudável, clima organizacional agradável, propício ao bem estar, satisfação e a motivação dos colaboradores, fazendo com que se sintam valorizados. Davis e Newstrom (2004, p.146) dizem que a proposta básica da QVT é desenvolver ambientes de trabalho tão bons para as pessoas como para a saúde econômica da organização.

Problemas decorrentes da falta tanto da QV como da QVT podem refletir negativamente na vida indivíduo, seja no ambiente de trabalho ou nos seus momentos de tempo livre e lazer, resultando em uma má produtividade, como também problemas de absenteísmo, rotatividade e saúde. Conte (2003) ressalta que a meta principal do programa de QVT é a conciliação dos interesses dos indivíduos e das organizações, ao melhorar a satisfação do trabalhador, melhora-se a produtividade da empresa.

A preocupação com a QV das pessoas assim como da organização em proporcionar QV no ambiente de trabalho vem sendo discutida por muitos pesquisadores e gestores como um diferencial nas organizações.

A abordagem em torno do tema QV e da QVT, vêm sendo tratada em muitos estudos levando em consideração sua relação. O Quadro 1, a seguir, traz as colocações de alguns pesquisadores sobre esta relação.

\begin{tabular}{|l|l|}
\multicolumn{2}{|c|}{ Quadro 1 - Autores que defendem a ideia de relação entre QV e QVT } \\
\hline $\begin{array}{l}\text { Loscocco e Roschelle } \\
\text { (1991) }\end{array}$ & $\begin{array}{l}\text { Propuseram que a qualidade de vida deve ser analisada como a resultante da } \\
\text { composição (vida social familiar + realidade do trabalho) e não separadamente. }\end{array}$ \\
\hline Grandjean (1998) & $\begin{array}{l}\text { "Existem vários levantamentos que dão margem à hipótese que há estreitos laços } \\
\text { entre a QVT e a QV em geral". }\end{array}$ \\
\hline Danna e Griffing (1999) & $\begin{array}{l}\text { Salientam que "o trabalho e a vida pessoal não são duas coisas separadas, mas } \\
\text { domínios inter-relacionados e entrelaçados com efeitos recíprocos um no outro". }\end{array}$ \\
\hline Nahas (2006) & $\begin{array}{l}\text { "Pelo menos duas realidades se interpõe em nosso dia-a-dia e podem ser } \\
\text { consideradas no estudo da qualidade de vida: a realidade da vida social familiar (aí } \\
\text { incluindo o lazer) e a realidade do trabalho". }\end{array}$ \\
\hline Cooper (2005) & $\begin{array}{l}\text { Discorre sobre a percepção que os gerentes têm sobre as muitas horas de trabalho } \\
\text { onde "69\% destes executivos relatam que estas horas prejudicam sua saúde, 77\% } \\
\text { que afetam de forma adversa seu relacionamento com os filhos, 72\% que } \\
\text { prejudicam seu relacionamento com seu parceiro". }\end{array}$ \\
\hline Vasconcelos (2008) & $\begin{array}{l}\text { Apresentou estudos (DIEGUES, 2004; FRANÇA, 2006 e ARANHA, 2007) e } \\
\text { constatou que subir na carreira é terrivelmente devastador a QV e a saúde de } \\
\text { homens e também de mulheres. }\end{array}$ \\
\hline Timossi (2009) & $\begin{array}{l}\text { Conclui que correlacionar QVT e QV estão de acordo com a premissa atual de } \\
\text { gestão de pessoas, pois possibilita avaliar a influência de qualquer critério de QVT } \\
\text { sobre a QV geral e também inversamente. }\end{array}$ \\
\hline
\end{tabular}

Fonte: Adaptado de Timossi, 2009.

Analisando o Quadro 1, é possível perceber que os estudos em torno da relação de QV e QVT já foram e continuam sendo discutidos. 
Timossi (2009) evidência que ambas - QV e QVT - podem ser influenciadas por vários aspectos. O conhecimento dos fatores que estão presentes na vida dos colaboradores e que lhes causam certa insatisfação pode fornecer subsídios para que a empresa possa agir de forma coerente na tomada de decisão, contribuindo para que ocorra melhoria na vida, levando ao melhor desempenho dentro da organização.

\section{Metodologia}

Para atender os objetivos desta pesquisa, utilizou-se do banco de dados da pesquisa realizada por Timossi (2009), em quatro empresas do ramo de laticínios localizadas no estado do Paraná, onde foram analisadas a relação entre a QV e QVT.

As quatro empresas do ramo de laticínio foram selecionadas de acordo com seu porte em micro, pequena, média e grande empresa. Optou-se por escolher mais de uma empresa, pois o objetivo não foi fazer o retrato de uma organização mais de um mesmo setor produtivo. Fizeram parte desta população os níveis: diretores e gerência; colaboradores administrativos e setor produtivo (TIMOSSI, 2009).

Foram entrevistados ao todo 548 colaboradores da indústria alimentícia no ramo de laticínio, investigados através da aplicação simultânea dos instrumentos: o WHOQOL -100 e o modelo de Walton. O Quadro 2 a seguir apresenta o número de trabalhadores avaliados em cada empresa.

Quadro 2 - População em cada empresa

\begin{tabular}{|l|c|l|}
\hline Empresa & $\begin{array}{l}\text { N. de colaboradores } \\
\text { utilizados }\end{array}$ & \multicolumn{1}{c|}{ Questionários utilizados } \\
\hline MICRO & 6 & Todos os questionários foram utilizados \\
\hline PEQUENA & 20 & 1 questionário descartado por preenchimento inadequado \\
\hline MEDIA & 222 & 5 foram descartados por preenchimento incorreto, e 3 não retornaram \\
\hline GRANDE & 300 & A empresa liberou 301 colaboradores e 1 questionário foi descartado. \\
\hline
\end{tabular}

Fonte: Timossi, 2009, p. 87

Quanto às características sociodemográficas dos colaboradores pesquisados serão apresentadas na Tabela 1.

Tabela 1- Características sociodemográficas dos colaboradores

\begin{tabular}{lccc}
\hline Características & & N & \% \\
\hline Masculino & Gênero & 396 & $72 \%$ \\
Feminino & & 152 & $28 \%$ \\
& Faixa Etária & & \\
$18-29$ & 303 & $55 \%$ \\
$30-39$ & 153 & $28 \%$ \\
$40-49$ & 75 & $14 \%$ \\
$50-64$ & 17 & $3 \%$ \\
Média Masculina 30 anos & &
\end{tabular}




\section{Nível Educacional (*)}

Ensino fundamental incompleto Ensino fundamental completo $\quad 48 \quad 9 \%$

Ensino médio completo $\quad 150 \quad 28 \%$

Ensino superior completo $\quad 286 \quad 53 \%$

Pós Graduação completa $\quad 48 \quad 9 \%$

$7 \quad 1 \%$

Solteiro $\quad 186 \quad 35 \%$

Casado $320 \quad 60 \%$

Separado/Divorciado $\quad 26 \quad 5 \%$

$\begin{array}{lll}\text { Viúvo } & 2 & 0,3 \%\end{array}$

Filhos (***) $\quad 238 \quad 46 \%$

$\begin{array}{lll}\text { Sim } & 238 & 46 \% \\ \text { Não } & 300 & 55 \%\end{array}$

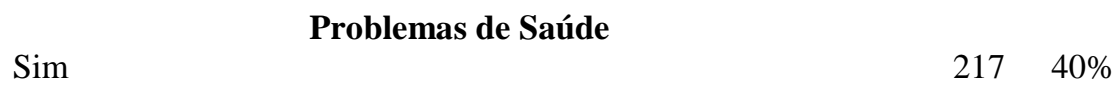

$\begin{array}{lll}\text { Não } & 331 & 60 \%\end{array}$

Fonte: Timossi, 2009.

(*) 9 colaboradores não relataram seu nível educacional.

(**) 14 colaboradores não relataram seu estado civil.

(***) 10 colaboradores não relataram à quantidade de filhos.

\subsection{Instrumento para a Qualidade de Vida: WHOQOL - 100}

O WHOQOL é um instrumento de avaliação de qualidade de vida composto por 100 itens e está disponível em 20 idiomas. A versão em português do WHOQOL foi desenvolvida no centro WHOQOL para o Brasil, no departamento de Psiquiatria e Medicina Legal da Universidade Federal do Rio Grande do Sul, sob a coordenação do Dr. Marcelo Pio de Almeida Fleck (WHOQOL GROUP, 1998).

Trata-se de um instrumento que questiona sobre como a pessoa tem se sentido em relação a sua qualidade de vida, saúde, e outras áreas afins. É composto por 100 questões, as quais é seccionado em 24 grupos de quatro questões cada, que se denomina por "facetas", um determinado número de facetas constituí um domínio, o instrumento baseasse em seis domínios que são: domínio físico; domínio psicológico; nível de independência; relações sociais, meio-ambiente e; espiritualidade / religião / crenças pessoais.

Existem quatro perguntas que não fazem parte das facetas e se referem às questões gerais sobre QV. A seguir, verificam-se os seis domínios e as 24 facetas que compõem o WHOQOL - 100.

Quadro 3- Domínios e facetas do WHOQOL-100

\begin{tabular}{|l|l|}
\hline \multicolumn{2}{|c|}{ Domínios e Facetas do WHOQOL- 100 } \\
\hline Domínio I - Domínio físico & Domínio IV - Relação sociais \\
1. Dor e desconforto & 13. Relações pessoais \\
2. Energia e Fadiga & 14. Suporte (apoio) social \\
3. Sono e repouso & 15. Atividade Sexual \\
\hline Domínio II - Domínio psicológico & Domínio V - Ambiente \\
4. Sentimentos positivos & 16. Segurança física e proteção \\
5. Pensar, aprender, memória e concentração & 17. Ambiente no lar \\
6. Auto - estima & 18. Recursos financeiros \\
\hline
\end{tabular}




\begin{tabular}{|l|l|}
\hline 7. Imagem corporal e aparência & $\begin{array}{l}\text { 19. Cuidados de saúde e sociais: disponibilidade e qualidade } \\
\text { 8. Sentimentos negativos }\end{array}$ \\
& $\begin{array}{l}\text { 20. Oportunidade de adquirir novas informações e habilidades } \\
\text { 21. Participação em, e oportunidades de recreação/lazer } \\
\text { 22. Ambiente físico: (poluição/ ruído/transito/clima) } \\
\text { 23. Transporte }\end{array}$ \\
\hline $\begin{array}{l}\text { Domínio III - Nível de independência } \\
\text { 9. Mobilidade }\end{array}$ & $\begin{array}{l}\text { Domínio VI - Aspectos espirituais/ religião/ crenças pessoais } \\
\text { 10. Atividade da vida cotidiana }\end{array}$ \\
$\begin{array}{l}\text { 11. Dependência de medicação } \\
\text { 12. Capacidade para o trabalho }\end{array}$ & \\
\hline
\end{tabular}

Fonte: Fleck et al. (1999)

Quanto aos resultados apresentados em cada domínio, estes produzem um escore médio que indica a percepção dos avaliados com a QV, neste aspecto em particular. Estes escores estão escalonados numa direção positiva, onde quanto maior o escore maior a QV neste domínio.

A versão do WHOQOL apresenta escores numa faixa de 4 a 20 pontos, que podem ser convertidos para uma escala de 0 a 100.

\subsection{Instrumento para a Qualidade de Vida no Trabalho: Walton}

Para investigar a QVT, utilizou-se o modelo adaptado de Walton (1973), um dos modelos mais utilizados e relevantes na avaliação da QVT. De acordo com Walton (1973), a insatisfação com a vida profissional é um problema que afeta quase todos os colaboradores, em um momento ou outro, isso independe de sua posição ou status. Os gerentes buscam reduzir a insatisfação com o trabalho em todos os níveis organizacionais, inclusive os seus próprios.

O modelo de Walton (1973) é o que melhor enfatiza questões relacionadas ao trabalho, priorizando alguns fatores como: condições físicas, aspectos de segurança e remuneração. Por sua complexidade, este modelo foi escolhido para a avaliação da QVT. Walton (1973) não traz um questionário constituído, mas um conjunto de dimensões, então Timossi et al., 2008 elaboraram um questionário, baseado nas dimensões apresentados por Walton para avaliarem a QVT dos colaboradores.

O modelo é constituído por oito dimensões e/ou critérios, os quais abrangem aspectos básicos das situações no trabalho. Os critérios encontram-se no Quadro 4, a seguir: 
Quadro 4- Critérios de Walton para Qualidade de Vida no Trabalho

\begin{tabular}{|c|c|c|}
\hline Critério & Indicadores & Descrição \\
\hline $\begin{array}{l}\text { Compensação justa e } \\
\text { adequada }\end{array}$ & $\begin{array}{l}\text { Salário } \\
\text { Jornada de trabalho }\end{array}$ & $\begin{array}{ll}\text { - } & \text { Referente também à remuneração } \\
\text { - } & \text { Carga horária de trabalho }\end{array}$ \\
\hline Condições de trabalho & $\begin{array}{l}\text { Ambiente físico } \\
\text { Salubridade }\end{array}$ & $\begin{array}{ll}\text { - } & \text { No sentido de conforto ergonômico } \\
\text { - } & \text { Ausência de exposição a riscos } \\
\text { ocupacionais }\end{array}$ \\
\hline $\begin{array}{l}\text { Uso e desenvolvimento } \\
\text { das capacidades pessoais }\end{array}$ & $\begin{array}{l}\text { Autonomia } \\
\text { Estima } \\
\text { Capacitação múltipla } \\
\text { Informações sobre o trabalho }\end{array}$ & $\begin{array}{l}\text { - } \\
\text { - } \quad \text { O quanto se sente querido por parte } \\
\text { dos colegas } \\
\text { - } \quad \text { Qualificação especifica e geral para o } \\
\text { exercício da função } \\
\text { De que forma e em que profundidade } \\
\text { se é informado sobre o trabalho }\end{array}$ \\
\hline $\begin{array}{l}\text { Oportunidade de } \\
\text { crescimento e segurança }\end{array}$ & $\begin{array}{l}\text { Carreira } \\
\text { Desenvolvimento pessoal } \\
\text { Estabilidade no emprego }\end{array}$ & $\begin{array}{ll}\text { - } & \text { Movimento de ascensão profissional } \\
\text { - } & \text { Melhoria em performance } \\
\text { - } & \text { Risco de demissão }\end{array}$ \\
\hline $\begin{array}{l}\text { Integração social na } \\
\text { organização }\end{array}$ & $\begin{array}{l}\text { Ausência de preconceitos } \\
\text { Habilidade social } \\
\text { Valores comunitários }\end{array}$ & $\begin{array}{ll}\text { - } & \text { Inclusão ou Exclusão na empresa } \\
\text { - } & \text { Educação e diplomacia } \\
\text { - } & \text { Valorização das tarefas pela empresa }\end{array}$ \\
\hline Cidadania & $\begin{array}{l}\text { Direitos garantidos } \\
\text { Privacidade } \\
\text { Imparcialidade }\end{array}$ & $\begin{array}{l}\text { - } \quad \text { Pagamentos, férias, seguros etc. } \\
\text { - Não invasão na documentação e } \\
\text { decisões } \\
\text { - } \begin{array}{l}\text { Ausência de subjetividade e decisões } \\
\text { objetivas }\end{array}\end{array}$ \\
\hline $\begin{array}{l}\text { Trabalho e espaço total de } \\
\text { vida }\end{array}$ & $\begin{array}{l}\text { Liberdade de expressão } \\
\text { Vida pessoal preservada } \\
\text { Horários previsíveis }\end{array}$ & $\begin{array}{ll}\text { - } & \text { Revelação das opiniões } \\
\text { - } & \text { Ausência de interferência na vida } \\
& \text { pessoal } \\
\text { - } & \text { Uso do tempo pessoal-profissional }\end{array}$ \\
\hline $\begin{array}{l}\text { Relevância social do } \\
\text { trabalho }\end{array}$ & $\begin{array}{l}\text { Imagem da empresa } \\
\text { Responsabilidade social da } \\
\text { empresa }\end{array}$ & $\begin{array}{l}\text { - } \quad \text { Credibilidade da empresa na } \\
\text { comunidade } \\
\text { - } \quad \text { Preservação ambiental, geração de } \\
\text { empregos, metaqualidade }\end{array}$ \\
\hline
\end{tabular}

Fonte: Limongi - França (1996), adaptado de Walton (1975)

O modelo de Walton foi priorizado e selecionado para a coleta de dados, pois os seus oito critérios abrangem com uma boa amplitude aspectos básicos das situações de trabalho e pode ser aplicado nos mais diferentes tipos de organização de trabalho (TIMOSSI, 2009).

\subsection{Escala de respostas do WHOQOL e Walton}

As respostas das questões do WHOQOL foram formuladas para uma escala de respostas do tipo likert, composta por cinco elementos, com quatro escala de respostas:

- Intensidade (nada/ muito pouco/ mais ou menos/ bastante/ extremamente);

- Capacidade (nada/ muito pouco/ médio/ muito/ completamente);

- Frequência (nunca/ raramente/ às vezes/ repetidamente/ sempre) e; 
- Avaliação (muito insatisfeito - muito satisfeito; muito ruim - muito bom; muito feliz- muito infeliz).

De acordo com o grupo WHOQOL (1998) não existe uma normalização padrão para os resultados do WHOQOL-100, tendo em vista a necessidade desta classificação adotou-se uma escala centesimal, composta de cinco medianas: 10, 30, 50, 70 e 90, (SANTOS, 2007).

A escala proposta para o WHOQOL pode ser verificada na figura1.

Figura 1- Escala de resposta QV

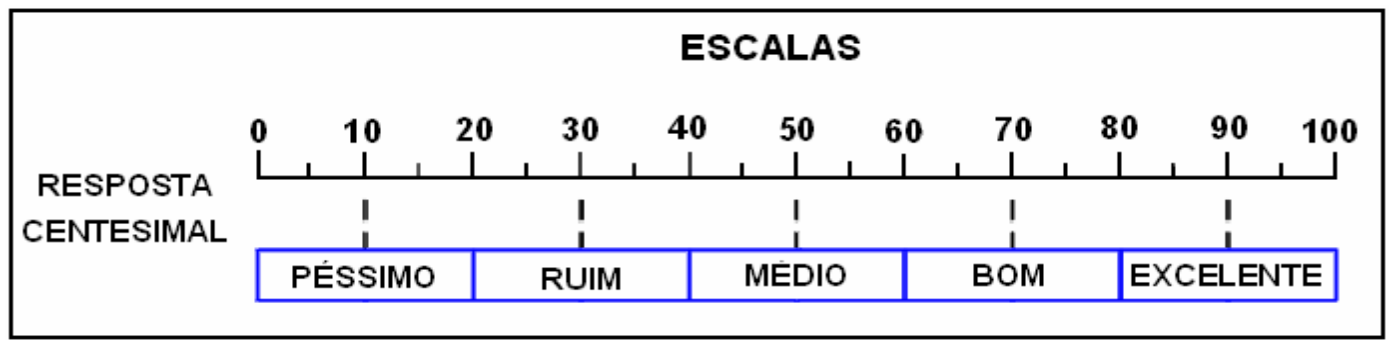

Fonte: Santos, 2007.

O modelo de Walton não é um questionário, mas um conjunto de critérios e não propõem uma escala de resposta, sendo assim, procurando padronizar os resultados de QV e QVT em uma mesma escala optou-se por basear o modelo de resposta de QVT no mesmo modelo utilizado pelo instrumento WHOQOL-100, em escalas centesimais (0 a 100) (TIMOSSI, 2009).

A classificação da QVT pode ser ilustrada conforme a Figura 2 a seguir:

Figura 2- Escala de respostas de QVT

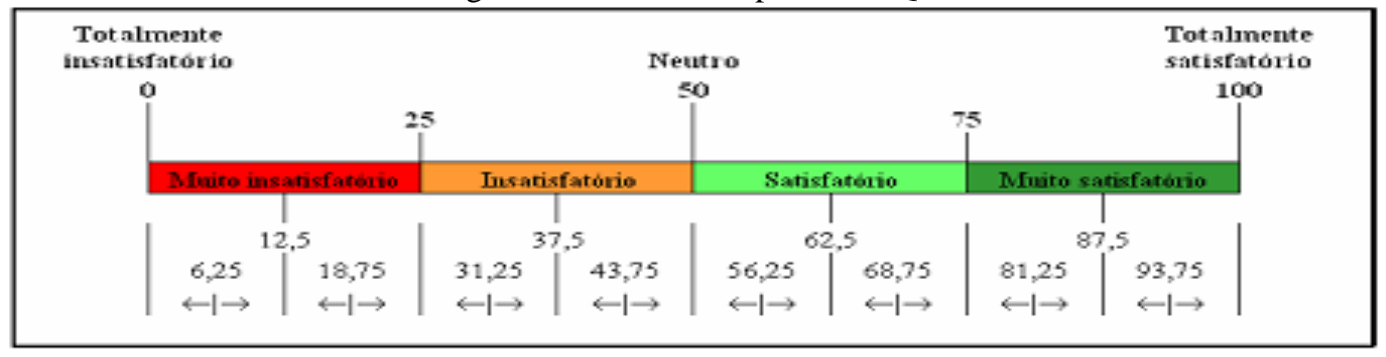

Fonte: Timossi et al., 2008

$\mathrm{Na}$ adaptação foi utilizada uma escala do tipo Likert, composta por 5 pontos, onde os valores elencados eram de $0 \%, 25 \%, 50 \%, 75 \%$ e 100\%, onde estes níveis acabam configurando a satisfação ou insatisfação da QVT (TIMOSSI et al., 2008). A interpretação desta escala compreende que os valores de 0 a 50\%, insatisfação na QVT e de 50 a 100\% como satisfação na QVT.

\subsection{Teste de Independência entre as variáveis}

A estatística utilizada foi o teste de independência, que segundo Triola (2008) testa a hipótese nula de que não há associação entre a variável linha e a variável coluna em uma tabela de 
contingência. Esta tabela de contingência é uma tabela na qual as frequências correspondem a duas variáveis.

Com base na análise dos questionários, conforme descrito no item 3.1 e 3.2, o instrumento WHOQOL-100 para a QV está dividido em seis domínios e o instrumento baseado no modelo de Walton para QVT está dividido em oito critérios. Na realização do teste de independência da relação entre uma variável dependente e uma ou mais variáveis independentes, a variável é dicotômica, ou seja, uma variável com duas possibilidades de resposta.

Recorreu-se ao teste de Independência Qui-Quadrado, o qual busca medir a associação entre duas variáveis, para examinar as associações de influência ou dependência, entre os seis domínios da QV com a QVT geral e, as associações entre os 8 critérios da QVT com a QV geral.

Como os instrumentos (WHOQOL/Walton) aplicados nesta pesquisa estão numa escala likert de 5 pontos, conforme visto no item 3.3, e o teste de independência exige há necessidade de variáveis dicotômicas, atribuiu-se a seguinte escala: escores acima de 50 satisfeito, igual a 50 neutro e abaixo de 50 insatisfeito. Como não ocorreu nenhum caso de neutro, atribui-se 1 para a ocorrência de satisfação e 0 para a ocorrência de Insatisfação.

O teste de independência nos fornece o valor de P, que segundo Devore (2009), trata-se do menor nível de significância em que a hipótese nula seria rejeitada, quando um procedimento de teste especificado é usado em um determinado conjunto de dados. É, portanto o menor nível em que os dados são significativos.

No teste de independência, a linha e a coluna de variáveis são independentes uns dos outros, esta é a hipótese nula. Temos neste teste as seguintes hipóteses:

- Para os domínios da QV com a QVT geral, em que a variável dependente é a QVT e os domínios são as variáveis independentes tem-se:

Hipótese nula $\left(\mathrm{H}_{0}\right)$ : o domínio analisado é independente da QVT geral.

Hipótese alternativa $\left(\mathrm{H}_{1}\right)$ : o domínio analisado e a QVT geral são dependentes.

- Para os critérios da QVT com a QV geral, em que a variável dependente é a QV e os critérios da QVT são as variáveis independentes tem-se:

Hipótese nula $\left(\mathrm{H}_{0}\right)$ : o critério analisado é independente da QV geral.

Hipótese alternativa $\left(\mathrm{H}_{1}\right)$ : o critério analisado e a QV geral são dependentes.

Definido as hipóteses (nula e alternativa) é preciso adotar um nível de significância identificando o valor de $\alpha$ que neste caso será $\alpha \leq 0,05$.

O teste qui-quadrado é representado matematicamente pela seguinte expressão (TRIOLA, 2008):

$$
\chi^{2}=\sum \frac{\left.(o-e)\right|^{2}}{e}
$$


Onde:

$X^{2}=$ Qui Quadrado

$\mathrm{o}=$ frequência observada por cada classe

$\mathrm{e}=$ frequência esperada para cada classe.

A partir da análise estatística dos dados, utilizando-se do teste de independência com a hipótese e o nível de significância, foi possível chegar à influência estatística existente entre os critérios e a QV geral e os domínios e a QVT geral.

\section{Resultados e discussão}

Os valores obtidos através do teste de independência (ver equação), envolvendo todas as 14 variáveis encontram-se nas Tabelas 3 e 4. Foi possível verificar com um nível de significância $\alpha \leq$ 0,05, quais variáveis independentes possuem influência significativa em relação às variáveis dependentes.

Tabela 3 - Domínios da QV com a QVT Geral

\begin{tabular}{lll}
\hline Domínios & \multicolumn{1}{c}{ Qui-quadrado } & \multicolumn{1}{c}{ Valor de $\boldsymbol{P}$} \\
\hline D. Físico & 42,940 & $\leq 0,01$ \\
D. Psicológico & 38,951 & $\leq 0,01$ \\
D. Nível de Independência & 10,633 & $\leq 0,01$ \\
D. Relações Sociais & 29,738 & $\leq 0,01$ \\
D. Meio Ambiente & 43,675 & $\leq 0,01$ \\
D. Aspectos Espirituais/crenças & $\mathbf{3 , 6 0 3}$ & $\mathbf{0 , 0 5 8}$ \\
\hline
\end{tabular}

Fonte: Autoria própria, 2011

Das seis variáveis (domínios) investigadas, cinco apresentaram dependência significativa.

Estas são as que o resultado da análise apresentou valor de $p<0,01$. Portanto, essa dependência pode ser verificada com no mínimo 99,9\% de confiança.

Conforme a tabela 3, a única variável considerada independente de QVT foi o domínio "Espiritualidade" ( $\mathrm{p}=0,058)$, pois na análise teste de independência apresentou valor de $P$ maior que o nível de significância adotado, $\alpha=0,05$. É provável que o fato deste domínio não se apresentar significante, devido o instrumento WHOQOL-100 apresentar apenas quatro questões referentes a este domínio, sendo assim avaliado de forma incompleta para um conceito tão amplo.

Isto pode estar de acordo com Fleck (2008), o qual relata em seu trabalho que a OMS incluiu no seu instrumento WHOQOL-100, um domínio denominado Espiritualidade/ Religiosidade/Crenças Pessoais", composto por quatro questões que se mostraram insuficientes nos testes de campo realizado em vários centros.

$\mathrm{Na}$ tabela 4, a seguir, é apresentado o resumo da análise do teste de independência aplicado para os critérios da QVT e QV geral. 
Tabela 4 - Critérios da QVT com a QV Geral

\begin{tabular}{lcc}
\hline \multicolumn{1}{c}{ Critérios de QVT } & Qui-quadrado & Valor de $\boldsymbol{P}$ \\
\hline Comp. Justa e Adequada & 19,910 & $\leq 0,01$ \\
Cond. Trabalho & 10,622 & $\leq 0,01$ \\
Capacidades & 41,645 & $\leq 0,01$ \\
Oportunidades & 45,362 & $\leq 0,01$ \\
Integração Social & 74,691 & $\leq 0,01$ \\
Constitucionalismo & 44,928 & $\leq 0,01$ \\
Trabalho e Vida & 12,773 & $\leq 0,01$ \\
Relevância Social & 14,782 & $\leq 0,01$ \\
\hline
\end{tabular}

Fonte: Autoria própria, 2011

Das oito variáveis investigadas (critérios), todos os critérios apresentaram dependência significativa. Estas são as que o resultado da análise apresentou valor de $p<0,01$. Portanto, essa dependência pode ser verificada com no mínimo 99,9\% de confiança.

Neste caso foi observada dependência significativa entre todos os critérios de QVT e QV geral. De acordo com o valor de $P$ obtido na análise deste teste, rejeita-se a hipótese nula (independência entre as variáveis analisadas), concluindo que há evidência suficiente para garantir a afirmação de que os critérios de QVT e a QV geral são significativamente dependentes. Isso pode ser afirmado com no mínimo 99,9\% de confiança.

Verifica-se que esses resultados estão coerentes com os achados por Timossi (2009), que verificou a existência de correlação significativa entre critérios de QVT e QV geral e também entre os domínios de QV e QVT geral para a mesma população em estudo.

Timossi (2009) realizou dois procedimentos quanto a correlação, primeiramente selecionou os 8 critérios de QVT como variáveis independentes e o índice de QV geral como variável dependente, em segundo avaliou os 6 domínios de QV como variável independente e QVT geral como variável dependente.

Nas Tabelas 5 e 6, pode ser verificados os achados de Timossi (2009), onde considerando um n=548 (população analisada), $\alpha=0,01$ o coeficiente crítico de correlação de Pearson é 0,25.

$\mathrm{Na}$ Tabela 5, pode ser verificado o resultado obtido na análise do teste de independência apresentado neste trabalho e a comparação com os resultados obtidos por Timossi (2009) no que se refere à análise de correlação entre as variáveis de QV (domínios) com a QVT geral.

Tabela 5 - Resultados quanto à correlação entre os domínios de QV e a QVT geral

\begin{tabular}{lcc}
\hline \multicolumn{1}{c}{ Critérios de QV } & $\begin{array}{c}\text { Índice de QVT Geral } \\
\text { Coefic. Correl. } \mathbf{R} \boldsymbol{\alpha = \mathbf { 0 , 0 1 }}\end{array}$ & Valor de $\boldsymbol{P}$ \\
\hline D. Físico & 0,44 & Significativa \\
D. Psicológico & 0,42 & Significativa \\
D. Nível de Independência & 0,31 & Significativa \\
D. Relações Sociais & 0,40 & Significativa \\
D. Meio Ambiente & 0,55 & Significativa \\
D. Aspectos Espirituais/crenças & $\mathbf{0 , 2 2}$ & Não significante \\
\hline
\end{tabular}

Fonte: Timossi, 2009. 
Em relação à correlação da QVT geral com os seis domínios de QV, apenas o domínio “aspectos espirituais e crenças" não atingiu um coeficiente de correlação significativo com a QVT geral (coeficiente de correlação encontrado 0,22 < 0,25 coeficiente crítico) (TIMOSSI, 2009).

Conforme o teste de independência se confirma os resultados de Timossi (2009), que este domínio não é significante para a relação de influência com a QVT geral.

De acordo com a conclusão de Timossi (2009) se observa a total coerência nos seus achados com os encontrados na análise do teste de independência. O resultado dessa comparação deixa ainda mais evidente a relação existente entre os domínios (exceto domínio Espiritualidade) de QV e a QVT geral.

Na tabela 6 a seguir, o resultado obtido na análise do teste de independência e apresentado neste trabalho e comparado com os resultados obtidos por Timossi (2009) no que se refere à análise de correlação entre as variáveis de QVT (critérios) e de QVT geral.

Tabela 6- Resultados quanto à análise da correlação entre os critérios de QVT e a QV geral

\begin{tabular}{lcc}
\hline \multicolumn{1}{c}{ Critérios de QVT } & Coefic. Correl & Dependência \\
\hline Comp. Justa e Adequada & 0,38 & Significativa \\
Cond. Trabalho & 0,49 & Significativa \\
Capacidades & 0,48 & Significativa \\
Oportunidades & 0,40 & Significativa \\
Integração Social & 0,47 & Significativa \\
Constitucionalismo & 0,46 & Significativa \\
Trabalho e Vida & 0,44 & Significativa \\
Relevância Social & 0,40 & Significativa \\
\hline
\end{tabular}

Fonte: Adaptado de Timossi, 2009.

Timossi (2009) conclui que, de acordo com os coeficientes de correlação apresentados na tabela 6, todos os critérios de QVT apresentam correlação significativa (nível de significância de $0,01)$ com a QV geral.

Ainda considerando os resultados expostos na tabela 6, observa-se total coerência nos achados de Timossi (2009) com os encontrados na análise do teste de independência. O resultado dessa comparação deixa ainda mais evidente a forte relação existente entre os critérios de QVT e a QV geral.

\section{Conclusão}

Os estudos de QV e QVT precisam ser voltados para garantir melhorias de forma prática para os indivíduos e também para as organizações.

O objetivo de analisar a influência dos critérios da QVT na QV geral e dos domínios da QV na QVT geral dos colaboradores da indústria de laticínio foi alcançado devido a metodologia adotada. 
Através da análise dos dados com estes colaboradores, foi possível verificar a partir do teste de independência, quais as variáveis significativamente importantes para explicar a influência entre a QV e a QVT.

Conclui-se que todos os critérios da QVT parecem possuir influência significativa na QV destes colaboradores avaliados. Também verificamos que os domínios da QV, com exceção do domínio “Aspectos Espirituais e crenças”, possuem influência significativa na QVT destes colaboradores. A análise da influência entre QV e QVT poderá ajudar e apoiar estatisticamente na tomada de decisão dos gestores, direcionando de melhor forma os investimentos da empresa.

Em outras palavras, através dos resultados encontrados, a empresa poderá direcionar investimentos nos domínios da QV em busca de melhorias em sua QVT, o que irá refletir positivamente. Pois foi provada estatisticamente a influência existente entre ambas, este investimento estará gerando satisfação tanto para a empresa quanto para seus colaboradores.

\begin{abstract}
The aim of this paper is to analyze the influence between the criteria of quality of work life with the general quality of life, and between the domains of quality of life with the quality of work life of employees in the dairy industry. Identifying the criteria and domains dependent and significant. Methodology: data quality of life and quality of work life are from research conducted by Timossi (2009) through the simultaneous application of the WHOQOL-100 and Walton model adapted to portuguese. The sample consists of 548 employees. The analysis occurred with the test of independence on 14 variables. The results showed that there is influence between the eight criteria of the quality of work life with the general quality of life, and between five domains of quality of life with the general quality of work life. Only the domain "Spiritual Aspects and beliefs," showed no significant influence on the quality of work life. It was concluded that all the criteria of quality of work life have influenced the quality of life of employees assessed, as well as the domains of quality of life, except for the domain "Spiritual Aspects and beliefs," significantly influence the quality of work life. The company will target investments in quality of life in pursuit of improvements in their quality of life at work, which will reflect positively, as has been proven statistically the influence between the two, this investment will generate satisfaction for both the company and for its employees.
\end{abstract}

Key- words: Quality of Life, Quality of Life at Work: Test of independence; Dairy.

\title{
Referências
}

ARELlANO, Eliete Bernal. Avaliação dos programas de Qualidade de Vida no Trabalho - análise critica das praticas das organizações premiadas no Brasil. São Paulo, 2008. Tese de Doutorado. Programa de Nutrição Humana Aplicada - Universidade de São Paulo.

DEVORE, J. L. Probabilidade estatística: para engenharia e ciência. São Paulo: Pioneira Thomson Learning, 2006.

CONTE, Antonio Lazaro. Funcionários com qualidade de vida no trabalho são mais felizes e produzem mais. Revista FAE BUSINESS, n.7, p. 32-24, nov. 2003. 
DAVIS, K.. NEWSTRON, J. W. Comportamento humano no trabalho: uma abordagem organizacional. Tradução Eunice Lacava Kwasnicka. São Paulo: Thomson Pioneira, 2004.

FLECK, M. P. A.; et al. A avaliação da qualidade de vida: guia para profissionais da saúde. Porto Alegre: Artmed, 2008.

FLECK, M. P. A. et al. Aplicação da versão em português do instrumento de avaliação da qualidade de vida “WHOQOL-bref”. Revista de Saúde Pública, São Paulo, v. 34, n. 2, p.178-183, abr. 2000.

LIMONGI-FRANÇA A. C. Interfaces da Qualidade de Vida no Trabalho na Administração de Empresas: resultados. 1996. 220 f. Tese (Livre docência) - Faculdade de Economia, Administração e Contabilidade da Universidade de São Paulo. São Paulo, 1996.

Qualidade de vida no Trabalho - QVT: conceitos e práticas nas empresas da sociedade pósindustrial. 2 ed. São Paulo: Atlas, 2008.

MARTEL, J. P.. DUPUIS, G. Quality of work life: theoretical and methodological problems, and presentation of a new model and measurement instrument. Social Indicators Research. v. 77, p. 333-368, 2006.

\section{cross ${ }^{\text {ref }}$}

MINAYO, M. C. de S.; HARTZ, Z. M. de A.; BUSS, P. M. Qualidade de vida e saúde: um debate necessário. Rev. Ciência e Saúde Coletiva. v.5, n.1, p. 7-18, 2000.

cross ref

PICARELli, V. Gestão por competências. In: BOOG, G.; BOOG, M. (Orgs.). Manual de Gestão de Pessoas e Equipes: estratégias e tendências. São Paulo: Gente, p. 215-238, 2002.

RODRIGUES, M. V. Qualidade de vida no trabalho: Evolução e análise gerencial. Rio de Janeiro: Editora Vozes, 2008.

SANTOS, C. B. Análise dos resultados do WHOQOL-100 utilizando Data Mining. Ponta Grossa, 2007.108 f. Dissertação (Mestrado em Engenharia de Produção) - Universidade Tecnológica Federal do Paraná.

SHINYASHIKI R. Qualidade de vida é ter comprometimento. In: BOOG, G.; BOOG, M. (Orgs.). Manual de Gestão de Pessoas e Equipes: estratégias e tendências. São Paulo: Gente, p. 467-474, 2002.

TIMOSSI, L. S. Correlações entre a qualidade de vida e a qualidade de vida no trabalho em colaboradores das indústrias de laticínios. Ponta Grossa, 2009. 180 f. Dissertação (mestrado em Engenharia da Produção) - Universidade Tecnológica Federal do Paraná.

TIMOSSI, L. S.; PEDROSO, B.; FRANCISCO, A. C.; PILATTI, L. A. A avaliação da Qualidade de Vida no Trabalho: uma adaptação do modelo de Walton. In: Bioprodução: qualidade de vida e criação do conhecimento. Ponta Grossa, Ed. UTFPR, 2009.

TRIOLA, M. F. Introdução à estatística. 10. ed. Rio de Janeiro: LTC, 2008.

WALTON R. E. Quality of working life: what is it? Sloan Management Review, Cambridge, v. 15, n. 1, p. 11-21, 1973.

WHOQOL GROUP. Versão em português dos instrumentos de avaliação de qualidade de vida (WHOQOL) 1998. FAMED - Universidade Federal do Rio Grande do Sul. Disponível em: 〈http://www.ufrgs.br/psiq/whoqol1.html\#1> Acesso em 01/06/2009.

\section{Dados dos autores:}

\section{Nome completo: Rúbia Carla Maier}

Filiação institucional: UTFPR 
Departamento: PPGEP

Função ou cargo ocupado: Mestranda

Endereço completo para correspondência: AV. Ernani Batista Rosas, Conj. Habitacional Monteiro Lobato, Bloco 33 APT 23, J. Carvalho, Ponta Grossa- PR.

Telefones para contato: (42) 99266346

E-mail: rubiacmaier@yahoo.com.br

Nome completo: Guataçara dos Santos Junior

Filiação institucional: Universidade Tecnológica Federal do Paraná - UTFPR - Ponta Grossa Brasil

Departamento: PPGEP

Função ou cargo ocupado: Professor

Endereço completo para correspondência: Av Monteiro Lobato, s/n - Km 04 CEP 84016-210 Ponta Grossa - PR - Brasil

Telefones para contato: (42) 3220-4875

E-mail: guata@utfpr.edu.br

Nome completo: Luciana da Silva Timossi

Filiação institucional: Faculdade Dom Bosco - Curitiba

Função ou cargo ocupado: Professor

Endereço completo para correspondência: Rua Paulo Martins, 332, Mercês, 80710-010 - Curitiba, PR - Brasil

Telefones para contato: (41) 32185550

E-mail: lucianatimossi@yahoo.com.br

Enviado em: 01/08/2011

Aprovado em: 13/04/2012 